\title{
Veladuras. El servicio doméstico de niñas y jóvenes en la narrativa judicial de los años sesenta en Córdoba, Argentina*
}

\author{
Veladuras. Girls and Young Women in \\ Domestic Service in the Judicial Narrative \\ of the 1960s in Córdoba, Argentina
}

\author{
Agostina Gentili \\ (1) 0000-0001-9986-6098 \\ Universidad Nacional de Córdoba, Argentina \\ agosgentili@gmail.com
}

Resumen: A partir de fuentes judiciales, normativas, reglamentarias y televisivas, y conjugando operaciones de cuantificación, reducción de la escala de observación y contextualización, se analizan las mutaciones culturales experimentadas por las prácticas de colocación en el servicio doméstico y su particular vinculación con espacios de acogimiento y reclusión infantil y juvenil. Con la atención en el contenido y las formas del relato judicial, se argumenta que hacia los años sesenta del siglo xx las colocaciones adquieren el carácter de un componente residual de la cultura en el que ciertos espacios institucionales ocupaban un lugar crucial para hacerlas admisibles. Un ensayo de lectura en clave de larga duración que pone de relieve que el valor atribuido a la infancia en la Argentina contemporánea corrió el umbral de lo que podía ser dicho sin desterrar ese destino del horizonte de posibilidades de un segmento singular de la población infantil.

* El presente trabajo es una versión revisada y ampliada de la ponencia presentada en las jornadas Crimen y Sociedad. Diez años de Estudios sobre Policía, Delito y Justicia en Perspectiva Histórica, Bariloche, Argentina, octubre de 2016. Quiero agradecer los comentarios recibidos, especialmente a Cecilia Allemandi por su lectura minuciosa y entusiasta, y su orientación en el campo de estudios sobre el servicio doméstico. 
Palabras clave: servicio doméstico; institutos de menores; narrativa judicial; Argentina; historia de la infancia.

Abstract: On the basis of judicial, normative, regulatory and television sources, and by combining quantification operations, and reducing the scale of observation and contextualization, the cultural mutations experienced by placement practices in domestic service, this paper analyzes their particular connection with child and juvenile care and detention spaces. Focusing on the content and forms of the judicial account, the author argues that in the 1960s, placements acquired the nature of a residual component of a culture in which certain institutional spaces occupied a crucial place to make them admissible. This extended essay highlights the fact that the value attributed to children in contemporary Argentina derives from the threshold of what could be said without banishing that destiny from the horizon of possibilities of a specific segment of the child population.

Key words: domestic service; institutes for minors; judicial narrative; Argentina; history of childhood.

Fecha de recepción: 23 de noviembre de 2016 Fecha de aceptación: 29 de enero de 2018

Tita Funes, esa vecina nuestra, dijo "trajimos otra chica del norte".

Ese día mi madre lo contó en la mesa y mi padre dijo "para servir, las de mi tierra".

Dijo eso, y también dijo carajo.

María Teresa Andruetto, Veladuras.

\footnotetext{
armen era de una pequeña localidad del norte del país. Tenía ocho o diez años y hacía dos o tres que el señor Juárez la había traído a Córdoba al volver de una visita a su pueblo natal. Se lo había aconsejado el comisario, porque la niña no tenía familia y estaba con gente de pocos recursos y "vida irregular". El señor Juárez la trajo pero no pudo "enmendar sus malos hábitos", pensó en "devolverla" y Carmen se escapó. La policía la encontró meses
} 
después y esa vez fue una tía del señor Juárez quien intentó "corregirla". La niña volvió a escaparse y su segunda captura derivó en una presentación en las oficinas del juzgado de menores en junio de 1959. A partir de entonces, y hasta llegar a la mayoría de edad, Carmen vivió en distintos institutos, con estadías en el asilo del Buen Pastor y en dos hospitales psiquiátricos, escenarios de crianza y encierro a los que entraba y de los que salía tras "fugarse" de las casas en las que era colocada como empleada doméstica. ${ }^{1}$ El derrotero de Carmen por las oficinas judiciales no fue único. Ni en aquellos años ni muchos años atrás. Presente desde épocas coloniales, la ubicación de niñas y jóvenes en el servicio doméstico era una práctica asidua de la organización del mundo familiar, convertida en el destino recurrente de quienes transitaban las defensorías de menores y los asilos infantiles a fines del siglo XIX y principios del $\mathrm{xx}$, propiciado como una forma de preparación para la vida adulta de quienes quedaban a cargo del Estado. ${ }^{2}$ Las experiencias de Carmen y esas otras jóvenes de los años sesenta, revelan que las continuidades que las unían con el pasado remoto habían trazado un hilo invisible hecho de las mismas hebras pero con nuevos significados. Son justamente las mutaciones culturales que ciñeron a esas prácticas de larga duración las que este texto intenta interpretar.

Pensadas como un capítulo singular de la historia de la infancia -aunque sin desconocer los aportes historiográficos al campo de estudios sobre el

${ }^{1}$ Centro de Documentación Histórica. Fondo Menores. Caja 15, exp. 10. Archivo General de los Tribunales de Córdoba (en adelante AGTc), Argentina. Carmen es un nombre de fantasía escogido al azar aunque abrevando en los usos de aquellos años. Por respeto a su intimidad, lo mismo vale para todos aquellos que den cuenta de otras jóvenes que aparezcan en estas páginas.

${ }^{2}$ Distintos trabajos han dado cuenta de estas prácticas a lo largo de la historia y no sólo para el actual territorio argentino. Para la sociedad colonial cordobesa, contamos con las investigaciones de Ghirardi (2008); avanzando hacia la primera mitad del siglo xIx, Cicerchia (1990 y 1994) y Moreno (2004) dan cuenta de su pervivencia en la ciudad de Buenos Aires y la campaña bonaerense. El giro de siglo y la primera mitad del xx cuenta con un abanico nutrido de indagaciones sobre el tema, para el contexto porteño, suscitadas tanto en interrogantes propios de la historia de la infancia (Guy, 2002; Aversa, 2010; Freidenraij, 2015; Villalta, 2012; Flores, 2004; Lugones, 2004), como en investigaciones en torno al mercado de trabajo (Suriano, 2007; Allemandi, 2015 y Remedi, 2012). A ellos se suman las investigaciones de otras latitudes latinoamericanas, entre los que pueden rescatarse los aportes de Milanich (2009) para el siglo xIX chileno y de Ehrick (2009) para las primeras décadas del siglo xx uruguayo; de Sosenski (2010) y Blum (1998) para México y de Fonseca (1998) y Fávero Arend (2005) para Brasil. Por razones de espacio, esta indagación se focalizará sin embargo en el contexto argentino. 
servicio doméstico en Argentina ${ }^{3}$-, esas experiencias se sitúan en el territorio que circunda a la pregunta por las relaciones entre el mundo familiar y el mundo estatal. Una pregunta que impregna buena parte de los aportes de un campo reciente de estudios y en franco crecimiento, que rescató a la infancia como agente de la historia reconociendo la imbricación y retroalimentación constante de sus reflexiones respecto de aquellas que ofrecen quienes indagan las realidades familiares. ${ }^{4}$ Ambos órdenes, el de la familia y el del Estado, son pensados aquí como esferas que despliegan políticas específicas en torno a la infancia, entablando un juego de ponderaciones dirimido no sólo en términos de disciplinamiento sino también de complementariedad, negociaciones y disputas. Una partida nutrida de condiciones materiales de existencia e intervención, pero también de ideas, prácticas y convenciones portadoras de valores y concepciones sobre el género, la edad, la etnia y la clase social. ${ }^{5}$ Partiendo de esa conceptualización de la familia y del Estado que coloca en un primer plano la porosidad de ambas esferas -invitándonos a reconocer el modo en que ambas se condicionan y habilitan, se excluyen y amoldan-, estas páginas se dedican al análisis de las prácticas de colocación de niñas y jóvenes en el servicio doméstico, en un contexto espacial y temporal particular, pero ensayando una lectura en clave de larga duración.

Para ello, se vale de un conjunto de expedientes tramitados en los juzgados de menores de Córdoba, Argentina, entre 1957 y 1974 . Una parcela del mundo que tiene su punto de partida en la creación del fuero en la provincia y su clausura en los límites temporales de un fondo documental particular: el expediente de Carmen forma parte de un conjunto mayor de expedientes

${ }^{3}$ Al igual que los estudios sobre infancia, la conformación de un campo de estudios sobre el servicio doméstico es reciente y se nutre del aporte de diversas disciplinas; para un análisis sobre el particular, véase Allemandi (2017). En estas páginas se dialoga con un segmento particular que estudió el sector de la sociedad argentina del pasado.

${ }^{4}$ Las investigaciones sobre las colocaciones en el servicio doméstico dialogan con un conjunto mayor de indagaciones que rescataron a los niños y a las niñas como sujetos partícipes de la historia, evidenciando las potencialidades que la empresa ofrece para comprender las formas y los contenidos cambiantes tanto de las familias como de sus interacciones con el Estado. Para un análisis del campo de estudios sobre la infancia en Argentina, véanse Cosse, Llobet, Villalta y Zapiola (2012), para América Latina, Premo (2008). Sobre la historia de la familia y sus relaciones con el Estado como agente de sus transformaciones, véase Tamara Hareven (1995) para el escenario europeo, y Bjer y Boixadós (2004), pero también Cosse (2009), para el argentino.

5 El postulado se inspira tanto en las reflexiones de Michel Foucault (2009) sobre la gubernamentalidad como en las de Rayna Rapp (1979) y Pierre Bourdieu (1997) sobre la familia. 
que iban a ser eliminados, fueron rescatados y son hoy de acceso público, albergándose en el Archivo General de los Tribunales como Fondo Menores del Centro de Documentación Histórica del Poder Judicial. ${ }^{6}$ Se apela a operaciones de cuantificación, reducción de la escala de observación y contextualización inspiradas en los aportes de la microhistoria (Revel, 2015), de la historia social que abordó fuentes judiciales (Farge, 1991; Farge y Revel, 1998) y de Ann Twinam (2009) como referente de la historiografía de la familia. La historia de Carmen será el disparador de este relato en el que irán haciendo su aparición las experiencias de otras y otros jóvenes que transitaron las oficinas judiciales en camino a sus colocaciones; de niños y niñas que por allí pasaron con otros destinos; de las prescripciones normativas y reglamentarias de los juzgados y su órgano de colaboración y asistencia, la Dirección General de Menores, dependencia a cargo, además, de los establecimientos de acogida y reclusión infantiles y juveniles; y de los pareceres y las prácticas de quienes se ocupaban de esos espacios. El corpus documental con el que se trabaja tiene en su núcleo un conjunto de 434 solicitudes de guarda tramitadas en la Secretaría de Prevención de los dos juzgados de menores que existían en aquellos años en esta provincia mediterránea del país, 59 de las cuales involucraron concertaciones laborales. A ello se suma un puñado de fuentes normativas y datos censales, resoluciones de la Dirección General de Menores conservadas en el Archivo de Gobierno y noticias televisivas de la época, resguardadas en el Centro de Conservación y Documentación Audiovisual de la Universidad Nacional de Córdoba.

El estudio de esas fuentes estará dedicado a la reconstrucción de las experiencias de esas niñas y jóvenes colocadas en el servicio doméstico y las formas asumidas por los arbitrios institucionales y sus convalidaciones judiciales. Harán así su aparición diferentes espacios que cifraban esas experiencias, en particular los establecimientos de acogida y reclusión infantiles y juveniles, poniéndose de relieve las marcas que dejaban para hacer de la colocación un destino admisible. Con la atención puesta no sólo en el contenido sino también en el relato, se atenderá también a lo que Vianna (2010) define como la "narrativa judicial", invitándonos a "reflexionar sobre cómo

${ }^{6}$ Para un análisis de la reconstrucción y las características del fondo, véase Lugones y Rufer (2004), autores de la labor del rescate y la reorganización documental en cuestión. Para conocer las ideas que signaron la creación del fuero de menores en la provincia de Córdoba y su relación con las iniciativas y concreciones institucionales de Buenos Aires y otras provincias, véase Gentili (2015). 
ese material específico no sólo 'esconde' u omite datos, sino también produce la posibilidad de ciertos desenlaces, a partir de esas mismas omisiones y del peso burocrático que tienen los dichos convertidos en declaraciones y los peritajes de los especialistas" (p. 23). Recurriendo a los aportes de otros investigadores sobre las modalidades de esas prácticas en distintos contextos espaciales y temporales, se arriesga una lectura en clave de larga duración sobre las transformaciones del fenómeno. La reconstrucción no sólo pondrá en escena el modo en que los espacios por los que transitaban esas jóvenes signaban en buena medida sus condiciones de colocación y la pervivencia de estas prácticas en el escenario urbano. También sugerirá que hacia los años sesenta del siglo xx esas antiguas prácticas adquieren el carácter de lo que Raymond Williams (2009) define como un componente residual de la cultura, corolario de una mutación del valor social de la infancia que corrió los umbrales de lo que podía ser dicho y hecho por quienes la gobernaban.

\section{LAS COLOCACIONES DE CARMEN Y OTRAS JÓVENES DE LOS AÑOS SESENTA}

Cuando la policía llevó por primera vez a Carmen a las oficinas del juzgado, las explicaciones del señor Juárez y su tía bastaron para que las autoridades ordenaran su internación. No importaron las lagunas ni las contradicciones del relato de aquellas personas que la presentaron como una niña "incorregible". Sus "malos hábitos" eran para los Juárez el resultado de una infancia sin padres que la había llevado a convivir con personas "sin recursos y de vida irregular". Tenía "ciertas insuficiencias mentales" y "la madre [...] padecía de locura total y otros ascendientes eran alcohólicos consuetudinarios"; ${ }^{7}$ testimonios que develan que los Juárez sabían más de lo que estaban contando, o dijeron mucho más de lo que se dejó asentado. Lavalle, donde habían nacido la niña y su guardador, era un pueblo pequeño, y las declaraciones vertidas en las fojas del proceso se abrían a la posibilidad del conocimiento personal entre unas y otras familias con las que había crecido Carmen. El dato fue sin embargo innecesario para dar curso a la potestad del Estado sobre la vida de

${ }^{7}$ Para dar coherencia al relato y evitar un excesivo y distractor uso de corchetes, fueron llevados al pasado los tiempos verbales enunciados en presente por la narrativa judicial. Esta aclaración vale para todas las citas textuales provenientes de estas fuentes. 
esta niña. Para ello bastó que se dejaran asentados dos o tres trazos de una infancia en los márgenes, corolario de padres incapaces, por pobreza y condición, que habrían hecho infructuoso todo intento por "enmendarla". ¿A qué habían apelado para lograrlo?, ¿con qué intención la habían traído a la ciudad y qué había sido de ella entre sus fugas y sus capturas policiales?, nada se dijo que mereciera quedar por escrito.

Cuando el juzgado ordenó la internación de Carmen a la Dirección de Menores dispuso su ingreso en el Instituto Pablo Pizzurno. Creado por la Fundación Eva Perón en 1952, hacía dos años que había pasado a la administración del Estado provincial. Era uno de los más grandes que existían (y existieron) en la ciudad, tenía capacidad para 500 internos y 300 medio pupilos, niños y niñas no mayores de doce. Estaba a pocas cuadras del centro y tenía personal docente y departamentos propios de medicina, odontología, servicio social y psicología $;^{8}$ ubicación y dotación que lo diferenciaba de los otros establecimientos, en su mayoría diseminados en distintas localidades y organizados bajo la dirección de hombres o mujeres, en ocasiones sacerdotes o monjas, que contaban con el apoyo de celadores y del personal de cocina y limpieza; y estos, a su vez, de la colaboración que daban las niñas y los niños allí internados.

Las misas que se celebraban en la capilla del Pizzurno estaban abiertas a los vecinos de la ciudad. Y los vecinos de la ciudad tenían también oportunidad de encontrarse con el Instituto en el noticiero local cuando asumían nuevas autoridades. Los camarógrafos filmaban el evento siguiendo a funcionarios engominados que mostraban las instalaciones y a sus pequeños habitantes. Las rutinas de esos niños llegaban a los hogares cordobeses a través de imágenes montadas para la TV: vistiéndose con la ayuda de alguna chica no mucho más grandes que ellos, lavándose la cara en sanitarios uno al lado del otro, como las camas, con la ayuda de otra chica no mucho más grande que ellos; bebiendo de una evidente taza vacía en un comedor atestado de mesas, y en el patio, izando la bandera en formación escolar-militar. ${ }^{9}$ A las

${ }^{8}$ Minoridad, serie B, 1957/1958, T7, Res. 1.073, 30/12/57; Serie Gobierno, 1962, T35, Dto. 5.938 "A", 27-12-62. Archivo de Gobierno (AG), Argentina.

9 Archivo Fílmico Canal 10. Cassette 6, noticia 169, 12 de junio de 1969, título original: Actividades del Hogar Escuela Pablo Pizzurno; y cassette 10, noticia 119, 4 de septiembre de 1969, título original: Acto en el Instituto Pablo Pizzurno. Centro de Conservación y Documentación Audiovisual, Facultad de Artes y Facultad de Filosofía y Humanidades, Universidad Nacional de Córdoba (en adelante CDA), Argentina. 
misas del domingo y a las pantallas de TV se sumaban las visitas de vecinos en busca de algún niño o niña. Hacía casi un año que Carmen vivía allí cuando una mujer se presentó en el juzgado a pedir su guarda, para que la niña hiciera "compañía" a su madre y "le ayudara en algunos trabajos de la casa".

\section{Las colocaciones en el concierto de los pedidos de guarda}

En esos años las oficinas judiciales recibían a diario solicitudes de guarda. Así lo atestigua el fondo en estudio, que alberga una cantidad estimada de 1700 expedientes de la Secretaría que atendía estos pedidos, entre los que encontré 472 de aquellas solicitudes tras la revisión de 1090 procesos. No es posible estimar la cifra cierta de estos pedidos en esos años. No sólo por tratarse de un conjunto de expedientes rescatados del expurgo, también por sus modalidades de confección y archivo. Como los procesos eran usualmente identificados con el nombre de la Secretaría a cargo y no del asunto del que trataban, ${ }^{10}$ es infructuosa la comparación de aquel volumen con los libros de entrada de expedientes enviados por el juzgado al archivo, en los que se consigna la carátula de cada trámite iniciado; registros de los que, además, tampoco disponemos de una serie completa. Se podría comparar la representatividad de los ejemplares encontrados con las guardas concedidas a través de autos interlocutorios: el archivo dispone de todas estas resoluciones dictadas año con año por cada juzgado y Secretaría, pero la lectura de los expedientes nos enseña que una gran cantidad de guardas se concedían a través de decretos, un tipo de resolución del que no quedaba rastro más allá del expediente. La imposibilidad de conocer la cantidad efectiva de solicitudes termina así potenciando el valor testimonial de ese conjunto ajado del fenómeno, que nos dice que al menos cuatro de cada diez procesos en manos de aquellos funcionarios eran guardas.

Sin definición normativa explícita, la guarda era una figura jurídica que definía quién sería el responsable legal de un niño. A través de este trámite la autoridad judicial transfería el ejercicio de los derechos y las obligaciones de la patria potestad a personas que no eran sus titulares. Como no

${ }^{10}$ Sólo $15 \%$ de los 472 expedientes encontrados daban cuenta del trámite de guarda en su carátula; $16 \%$ no llevaba carátula alguna (sólo el nombre de los chicos y las chicas involucrados), 3\% estaban identificados como "N.N", y $63 \%$ había sido caratulado como "Prevención". 
existía en su forma compartida, aquella correspondía al padre de los hijos de uniones matrimoniales y a la madre sólo cuando el niño no había sido reconocido por el padre (Código Civil, 1956, art. 264, título III, pp. 58 y 831). En palabras de Vianna (2010), que estudió estos procesos en Río de Janeiro de la última década del siglo xx, las guardas "son situaciones que tratan de la elección de quién debe retener o mantener (conservar en su poder) a un niño, pero también cuidarlo y ejercer vigilancia" (p. 23). Ordenadas por recurrencias, el cuadro 1 retrata las razones que habrían motivado estos pedidos en las oficinas judiciales de Córdoba, según quiénes los hacían y en qué circunstancias se encontraban los niños. Vemos allí que las colocaciones ocurrían en tan sólo una de cada diez oportunidades en que se pedían guardas. La principal razón por la cual cursaban estas solicitudes eran distintos arreglos de crianza y tenencia, seguidos de lejos por los conflictos familiares (disputas entre padres e hijos o entre padres por la tenencia de los niños), y por la adopción un poco más allá.

Las colocaciones ocupaban un lugar marginal en ese abanico de razones por las que se pedían guardas, pero eran singularmente frecuentes cuando aquellas involucraban la salida de un Instituto. En el cuadro vemos que siete de cada diez solicitudes eran presentadas por quienes ya tenían a los niños consigo, y que esta recurrencia era inversamente proporcional a lo que ocurría cuando se trataba de una colocación. Los escenarios institucionales de donde provenían los niños estaban presentes en dos tercios de aquellas, en poco más de la mitad de las adopciones (aunque aquí los establecimientos de acogida infantil eran ampliamente superados por la participación de las maternidades y otros hospitales), y en tan sólo un quinto de los arreglos de crianza.

Cuando Carmen salió del Instituto con aquella mujer que buscaba en ella una compañía para su madre y una ayuda en las tareas de la casa, tendría once o doce años. Hasta ese momento su edad no era clara en las fojas del proceso pero era evidente que se trataba de una niña. La opacidad de su edad en el relato judicial y el interés explícito de su guardadora por el trabajo que Carmen podía prestar en su casa hacían de su salida del Instituto una experiencia singular en aquella composición amplia de motivos y circunstancias que desembocaban en solicitudes de guarda; composición en la que la edad y el género eran condiciones fundamentales de las formas y fórmulas de estos pedidos. Si en los primeros meses y años de vida la cantidad de niñas y niños en guarda era similar, hacia la adolescencia estas comienzan a predominar, 


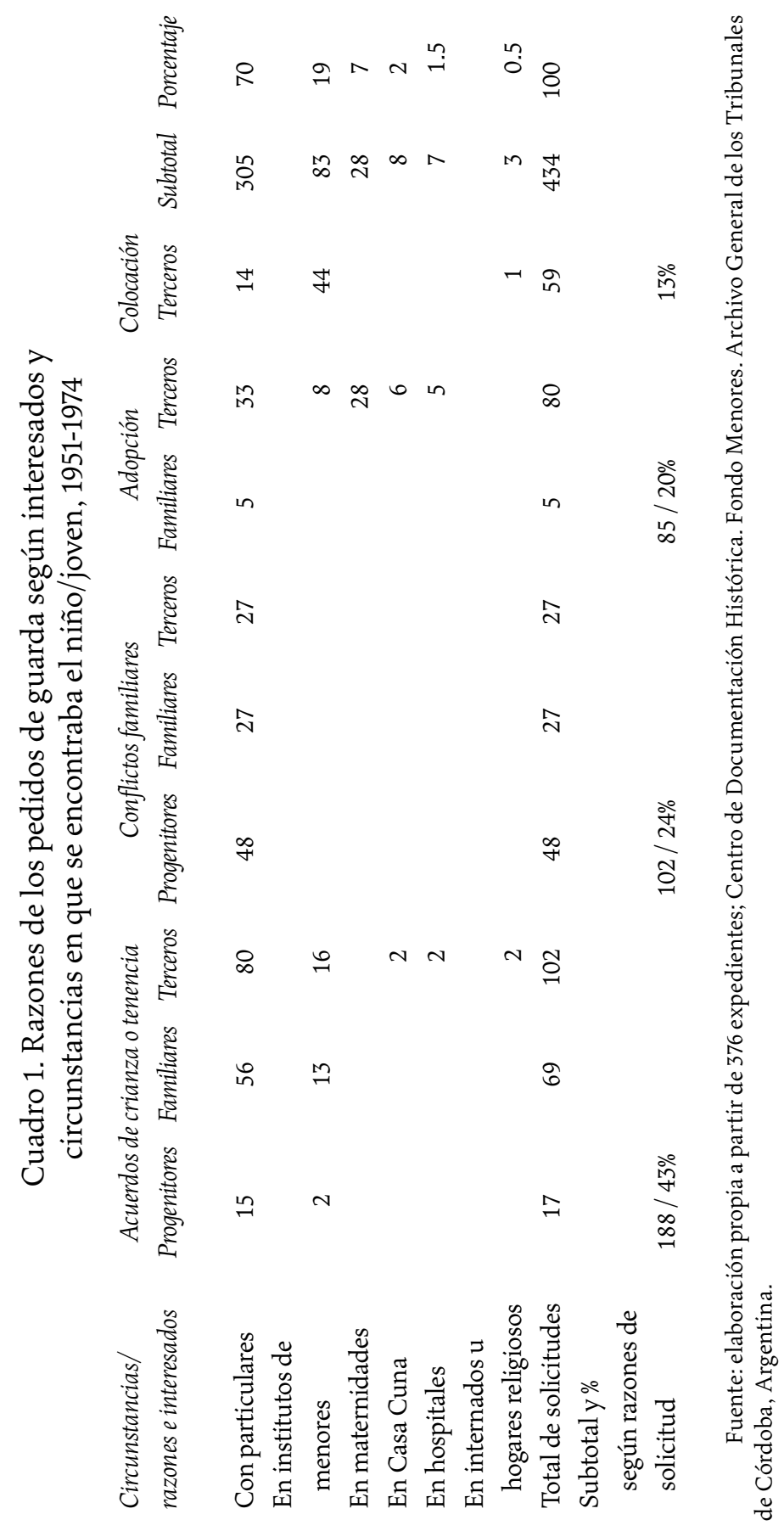


marcando una tendencia perfilada ya de los cinco a los doce (véase cuadro 2). Sólo en las adopciones encontramos que la cantidad de niñas y niños eran semejantes. Tratándose de arreglos diversos de crianza y tenencia, o de conflictos familiares, por cada dos niñas y jóvenes mujeres involucradas, teníamos a un niño o joven (aquí es necesaria una aclaración: 35 de esos 61 varones de trece a 20 años involucrados en legitimaciones de tenencia fueron misioneros estadunidenses de 19 y 20 años cuyas guardas fueran pedidas por un pastor de la Iglesia de los Santos de los Últimos Días en el marco de un trámite migratorio, de modo que sólo por la notable presencia de una práctica religiosa -y no familiar o institucional- es que en ese conjunto de solicitudes sobresalen los varones). Pero tratándose de una colocación, la distancia entre unas y otros se abría ampliamente: sólo un décimo de estos pedidos envolvió a varones.

Se trataba de cuatro jóvenes de quince y 16 . Tres habían estado internados en un instituto de menores y dos de ellos salían en guarda con concertaciones laborales en pequeños comercios tras escaparse y ser llevados por la policía ante las autoridades judiciales; ${ }^{11}$ el cuarto era colocado bajo una concertación familiar. ${ }^{12}$ El paso de estos chicos por instituciones de corte correccional hace suponer que buena parte de las colocaciones masculinas podrían estar tramitándose en las secretarías penales del fuero (Corrección y Sanción), de modo que esa reducida presencia de varones colocados no debería a priori asociarse a una disminución de la práctica. De hecho, la Dirección de Menores otorgaba a algunos chicos "becas de aprendizaje", eufemismo bajo el cual se les pagaba una suma de dinero a quienes, por su buena conducta, realizaban distintas labores en los institutos y otras dependencias de la repartición. ${ }^{13}$

Meses después de que Carmen saliera del instituto un asesor de menores quiso saber cómo estaba y si "realizaba tareas domésticas". Se pidió una encuesta ambiental a la Dirección de Menores y la asistente que visitó la casa contó que Carmen estaba "muy contenta", "muy bien vestida con zapatos y ropa de buena calidad", tenía "dos guardapolvos nuevos" para ir a la

\footnotetext{
${ }^{11}$ Centro de Documentación Histórica. Fondo Menores. Caja 3, exp. 3 y 32; caja 24, exp. 58. Agtc, Argentina.

${ }_{12}$ Centro de Documentación Histórica. Fondo Menores. Caja 1, exp. 23. AGTC, Argentina.

${ }_{13}$ Minoridad. Serie B, 1948, T. 3, Res. 237, 22/1/48 y Res. 249, 6/2/48; T. 39, 1971, Res. 3.542,14/5/71; T. 44, 1972, Res. 4.403, 13/6/72; y T. 46, 1972, Res. 4.655, 19/9/72 y Res. 4.685, 22/9/72, entre otras. AG, Argentina.
} 


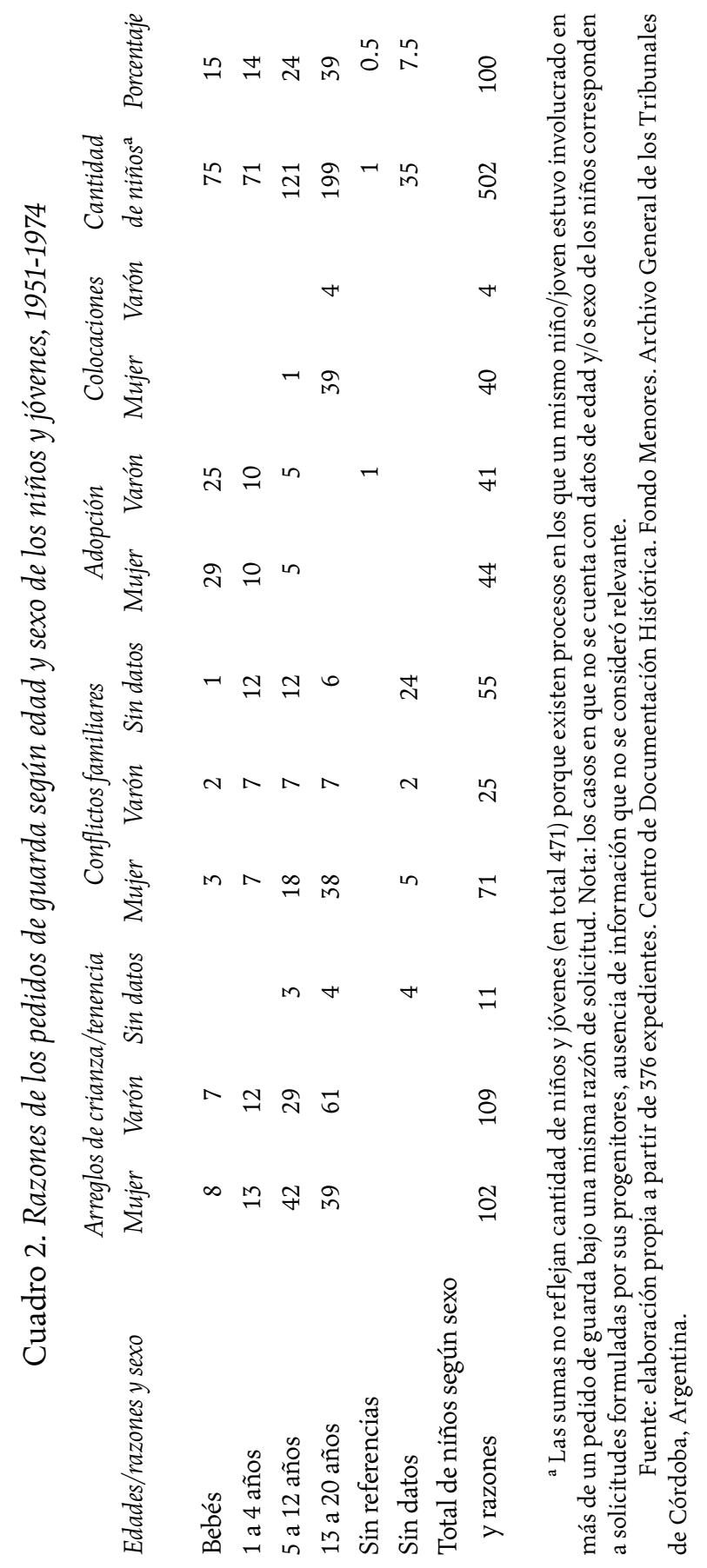


escuela, donde no sin dificultades cursaba el primer grado inferior. Confirmó también lo que la guardadora ya había dicho al pedir la guarda: en la casa ayudaba en las tareas de limpieza y hacía los mandados. La preocupación del asesor no sólo era un gesto que delataba una lectura poco atenta del expediente que tenía en su escritorio, sino también una vigilancia particular respecto de qué podía o no esperarse de la salida de una niña de un instituto. En 1958 la Dirección de Menores había prohibido que su personal retirara a niñas internadas para emplearlas en el servicio doméstico, inhibición que sin dudas pesaba en el arbitrio de guardas pedidas por particulares. De allí que la representación que el informe hacía de aquella niña que saliera a los once o doce años para ayudar en las tareas de la casa no admitiera mención alguna al pago de un salario; sus labores domésticas convivían con su escolarización y eran compensadas con ropas y guardapolvos nuevos. Aparecen aquí los primeros indicios de las mutaciones culturales que signaron el tránsito de las criadas a las colocadas en la larga duración. Pero para comprenderlas hay que avanzar un poco más en la historia de Carmen y otras chicas.

\section{Estadías institucionales}

$\mathrm{Al}$ año siguiente llegaba al juzgado un nuevo informe, mucho menos auspicioso: Carmen se había fugado por motivos que nuevamente no fueron develados y estaba internada en el Instituto Mercedes de San Martín. Ubicado a quince kilómetros de la ciudad en la localidad de Villa Allende, este instituto alojaba a niñas de seis a once años y tenía una escuela propia. En la época en que Carmen vivió allí se destinaba a chicas oligofrénicas de once a 18 años, en el marco de un nuevo rediseño de las funciones de cada instituto. ${ }^{14}$ Carmen continuaba yendo a la escuela pero cursaba recién el segundo grado a pesar de los años transcurridos y no podríamos afirmar -como dijera su anterior guardadora-, que fuera por problemas de aprendizaje: era "una alumna excelente con promedio de 8.37". También decían que tenía un "comportamiento regular: rebelde, desprolija, le agradaba aparentar, amante de usar lo ajeno, mentirosa, poco activa. De carácter esquivo, fingía estar siempre enferma, siempre disconforme." La alegría que tuviera, si la tuvo, parecería comenzar a declinar. En 1965, a tres años de su segunda internación, las asistentes socia-

14 Serie Gobierno. 1962, T35, Dto. 5.938 “A”, 27/12/62. AG, Argentina. 
les buscaban quién pudiera hacerse cargo de ella preguntando a sus anteriores guardadores si conocían a algún familiar. Seguía en segundo grado, le iba bien en la escuela y no era "molesta en el aula", pero sí, a los ojos de las informantes, "prolija y egoísta", "quería ser el centro para poder trabajar". Decían también que le faltaba "afecto", que "por no tener a nadie, se apegaba mucho a las cosas", y que no estaba en condiciones de salir del instituto por "carecer de familiares o de alguna persona capacitada moral y materialmente que quisiera retirarla". Con ese informe las autoridades judiciales conocieron la edad de Carmen, 6 años después de quedar a su cargo: contó que había nacido en 1949 en la ciudad de Corrientes, que no recordaba el nombre de su mamá ni de su papá, sólo sabía que eran cinco hermanos; había llegado a Córdoba cuando tenía seis años y desde entonces estuvo "alojada en diferentes lugares".

La asociación entre una internación prolongada y la falta de afectos, de la que el informe sólo hablaba entre líneas, forjaría en esos años una serie de iniciativas que procuraba por distintos medios que los niños vivieran en casas, junto con sus familias o bajo otras modalidades. Con epicentro en la desilusión por las experiencias de crianza en hogares colectivos, comenzaron a otorgarse asiduamente subsidios para que las familias afrontaran sus dificultades de crianza por carencias económicas ${ }^{15}$ y se inauguraron guarderías en distintos puntos de la capital y la provincia para que tuvieran dónde dejarlos en los horarios laborales. ${ }^{16}$ Una política en favor de una crianza en familia que tomó nueva forma con la creación de "pequeños hogares" y "familias sustitutas" -otras dos modalidades del otorgamiento de subsidios a matrimonios para que cuidaran de uno o de unos pocos niños- ${ }^{17}$ y con la im-

${ }^{15}$ Si bien en 1952 encontramos referencias a la concesión de subsidios familiares con dinero de la partida presupuestaria "para intensificar la campaña en pro de la minoridad desvalida", es a partir de 1968 que los subsidios familiares aparecen con una frecuencia regular y creciente en las resoluciones de la Dirección General de Menores, pergeñándose incluso un régimen particular para su otorgamiento, definido como eje rector de la política desplegada por la repartición durante el año 1969 (Minoridad. Serie B, T. 26, 1968, Res. 1.685, 1.823, 1.964 y 1.977; T. 32, 1969, Res. 2.542; Serie A, T. 6, 1970, Res. 13, 44, 46, 47, 49 y 54; Serie B, T. 33, 1970, Res. 2.670, 2.691, 2.090, 2.695, 2.696, 2.711, 2.713, 2.732, 2.760; T. 35, 1970, Res. 2.999; y T. 48, 1972, Res. 5.114, entre otros. AG, Argentina).

${ }^{16}$ Minoridad. Serie A, T. 5, 1966, Res. 343, 23/6/66; Serie B, T. 25, Res. 1.493, 28/6/67; Serie A, T. 7, 1970, Res. 106, 9/12/70; Serie B, T. 44, 1972, Res. 4.412, 15/6/72; Serie B, T. 46, 1972, Res. 4.697, 22/9/72; y Serie A, T. 9, 1973, Res. 31, 5/10/73. AG, Argentina.

${ }^{17}$ Minoridad, Serie B, T. 26, 1968, Res. 1.623, 4/1/68 y Res. 1.682, 7/3768; Serie B, T. 27, 1968, Res. 1.940, 29/10/68; Res, 1.966, 13/11/68; T28, 1969, Res. 2.038 y 2.039, 9/1/69; T30, 1969, Res. 2.275, 20/5/69 y Res. 2.283, 23/5/69; T. 33, 1970, Res. 2.790, 2/3/70; T. 34, 1970, Res. 2.941, 
plementación en 1972 de un explícito programa de desinstitucionalización. ${ }^{18}$ Iniciativas que eran un anuncio claro de la escasa confianza que quedaba en la apuesta hecha durante décadas a los hogares colectivos como solución al problema de la infancia en "peligro" o "peligrosa"; una apuesta depositada en los asilos de la sociedad civil a principios del siglo xx y en la intervención estatal directa con la creación de establecimientos propios desde los años treinta, que ni la orquestación de organismos especializados de centralización, ni la profesionalización de sus elencos y modos de intervención lograron dejar en pie. Así, cuando las asistentes sociales buscaban quién pudiera cuidar de Carmen, anunciaban en las comunicaciones cotidianas del gobierno estatal de la infancia lo que poco tiempo después terminaría por convertirse en un asunto de agenda pública. Una secuela de lo desalentadoras que podían llegar a ser las vidas de esos niños en esos escenarios, y de la consolidación de un modelo psicológico de crianza (Cosse, 2012) que trasvasaba la vida hogareña y familiar, colándose en las expectativas de quienes convivían a diario con niños a cargo del Estado.

A los pocos meses de aquel informe, Carmen fue otra vez al juzgado. Hacía un mes que estaba en el asilo del Buen Pastor; un pabellón de la cárcel de mujeres de la ciudad, gestionada desde siempre por la congregación católica que le diera su nombre, lugar al que llevaban a las chicas que tenían "problemas de conducta" o habían cometido algún delito. Carmen dijo que llegó allí porque se había "portado mal". ¿Qué había hecho para que esa fuera la que ella llamó su "penitencia"?, lo sabemos por un informe de años después: intentó suicidarse ( $\mathrm{Si}$ con el correr del proceso percibía que algo distinto estaba pasando, que la historia de Carmen perdía sus semejanzas con las de otras chicas que vivían en esos espacios, que estaba cada vez más desolada y no hacían falta palabras precisas para reconocerlo, al llegar al pasaje en el que decía purgar una penitencia en el Buen Pastor, su intento de suicidio se anticipó en forma de idea y el encuentro unas fojas más allá, con todas las letras, zanjó un surco en la lectura. Me llevé su tristeza a casa 50 años después y la certeza de que el relato judicial nos habla de muchas maneras. Por estar desperdigadas en un cierto vaho que desprenden sus fojas podrán no adqui-

30/4/70; Serie A, T. 7, 1970, Res. 127, 128, 129, 132, 133, 135 y 136, 23/12/70. AG, Argentina. Estos pequeños hogares venían siendo organizados a nivel nacional por el Consejo Nacional de Protección al Menor (Villalta, 2010).

${ }_{18}$ Minoridad. Serie B, T. 41, 1972, Res. 4.127, 28/2/72 y T. 45, 1972, Res. 4.576, 23/8/72, entre otras. AG, Argentina. 
rir la forma de una evidencia, pero será palpable para quien lea -con más de un sentido en escena- que hay allí niñas felices y aguerridas, como también las hay desesperadas. Esa tarde aprendí que hay maneras impensadas en que el archivo puede develarnos algún fragmento del pasado, que en este oficio el corazón también nos dice cosas.)

Carmen purgaba su penitencia cuando la llevaron otra vez al juzgado, no para saber qué había pasado sino para dejar asentado que hacía más de diez años que no sabía nada de su familia y "deseaba salir a trabajar para poder vestirse y ahorrar unos pesos para el día de mañana". En ese mismo acto montado en las que decían ser sus palabras, concedían su guarda a una mujer que se comprometía a darle "trato de familia". El desarraigo familiar y un "deseo" de ella hecho fórmula burocrática daban vía libre a una nueva concertación laboral a la que juzgado y guardadora nombraban como "trato de familia". Se dice poco de la materialidad de ese trato que en las páginas de un expediente sólo trasluce un informe de la asistente social que llega, seis meses después, signado por la "fuga" de Carmen "sin ningún motivo justificado" para una guardadora sorprendida, porque el comportamiento había sido "excelente" y ellos "la consideraban como una persona más". ¿De la familia?, ¿de la casa? Es en la ambivalencia de esa expresión que se cifran los nuevos significados de esa antigua práctica: una práctica que pervive sin que pueda ya ser enunciada abiertamente. Una ambivalencia que también atravesaba a las experiencias de las mujeres adultas ocupadas en el servicio doméstico. Como señala Pérez (2014 y 2015), la ambigüedad entre el mundo familiar y el mundo laboral que lo caracterizara -alimentada por su cercanía al trabajo doméstico femenino no remunerado-, había dilatado su reglamentación, sirvió para que lo fuera bajo el "régimen especial" en 1956, y fue una estrategia discursiva a la que apelaron empleadas, empleadoras(es) y autoridades judiciales convocadas en los años sesenta para resolver conflictos suscitados en torno a los derechos de las trabajadoras domésticas.

Carmen se presentó "voluntariamente" en las oficinas de la Dirección de Menores al irse de aquella casa y estaba en ese momento en el Hogar Santa Cruz. Creado en 1932 por la orden del Buen Pastor, ${ }^{19}$ este internado femenino pasó a depender de la Dirección de Menores en 1967 bajo la administración

19 Para un análisis de la infraestructura asistencial privada existente en la provincia entre 1930 y 1955, véase Ortiz Bergia (2012a y 2012b). 
de la congregación, ${ }^{20}$ y en 1969 se destinó a "la atención de 45 menores mujeres de catorce a 21 años, con coeficiente mental inferior al término medio que completaban su instrucción primaria y se capacitaban en tareas de taller de costura, tejido, repostería, etc." ${ }^{21}$ La asistente social que informó la situación de Carmen en ese momento, decía que era "mentirosa" y "poco trabajadora", que peleaba "constantemente" con sus compañeras y a veces reaccionaba con "violencia"; que quería estar en un instituto porque allí "no trabajaba y la trataban bien". Junto a aquel informe otro estudio psicológico la retrataba como una chica de "inteligencia fronteriza con disminución del conocimiento general" y "una edad de maduración inferior a la normal"; "ansiosa", "insegura" y "tímida", "carente de apoyo y de estabilidad"; consideraban que "estimulada adecuadamente" podría terminar su escolaridad y aprender un oficio práctico.

En algún momento, no queda claro cuándo (el expediente lleva por fecha noviembre de 1964 pero las actuaciones previas son de 1966), fue trasladada a otro internado religioso de Deán Funes, a 100 kilómetros de Córdoba. Tampoco queda muy claro qué habría pasado desde entonces. Al ser dada de alta de una estadía en el Hospital Neuropsiquiátrico - posiblemente tras su intento de suicidio-, en 1967 se pidió su alojamiento en el Buen Pastor. La Dirección de Menores recomendó en 1968 que "se la coloque en una casa, para que realice tareas domésticas y al mismo tiempo encuentre un hogar"; había una familia interesada y Carmen tendría "muchos deseos de salir y trabajar", esperaba "portarse bien y encontrar una casa donde la quieran". Pero al parecer este nuevo arbitrio de su reiterado destino laboral no llegó a concretarse. A los pocos meses se habría "ausentado sin permiso" del Centro de Orientación Juvenil -una institución privada que con subsidios de la Dirección de Menores administraba un "pequeño hogar" para madres menores $^{22}$, al que no sabemos cuándo y por qué había llegado, y era llevada al hospital psiquiátrico de Oliva porque padecía de "psicosis-epileptoides" y necesitaba "un tratamiento y control constantes" para no "poner en peligro la integridad física de sus compañeras y de sí misma”. En 1969 se presentaba en la Dirección de Menores y la alojaban otra vez en el Buen Pastor. Un año más

\footnotetext{
${ }^{20}$ Minoridad. Serie B, T. 25, 1967, Res. 1.603, 12/12/67. AG, Argentina.

${ }^{21}$ Minoridad. Serie B, T. 29, 1969, Res. 2.236, 18/4/69. AG, Argentina.

${ }^{22}$ Minoridad. Serie B, T. 27, 1968, Res. 1.966, 13/11/68 y T. 32, 1969, Res. 2.629, 11/12/69. AG, Argentina.
} 
tarde se pedía su captura a la policía: se habría fugado del Hogar de Menores Madres, un instituto estatal cuya administración también fuera delegada a la congregación del Buen Pastor en 1963. ${ }^{23}$

Así, de a jirones, concluye el relato judicial de la vida de Carmen en su paso por el sistema tutelar. Si siendo una niña su primera salida de un instituto para desempeñarse como doméstica en la casa de su guardadora desentonaba con los motivos reconocidos por los que se pedían guardas, al llegar a la adolescencia su derrotero institucional terminó acompasándose al de la mayoría de las jóvenes que en esos años fueron colocadas en el servicio doméstico. La ausencia de familiares a quienes poder recurrir, el desarraigo de la experiencia migratoria, el paso por un instituto a cargo de la congregación del Buen Pastor y la inestabilidad de esas concertaciones laborales, signadas por episodios de "fuga", eran rasgos singulares de las experiencias institucionales de colocación convalidadas por las autoridades judiciales del periodo. ${ }^{24}$

\section{Desarraigos migratorios y marcas institucionales}

Los procesos en los que se dejó algún testimonio al respecto permiten saber que, al igual que Carmen, otras quince chicas colocadas en el servicio doméstico eran inmigrantes. Diez provenían del interior de la provincia, ${ }^{25}$ cuatro de provincias de las regiones noreste y noroeste, ${ }^{26} \mathrm{y}$ una de Bolivia. ${ }^{27}$ Como en otros periodos de su historia, Córdoba se caracterizó en aquellos años por ser una provincia receptora de inmigrantes internos, en un cuadro general de esos movimientos que revela que la significación de las procedencias de aquellas jóvenes era cultural y no demográfica. En los años sesenta, dos tercios de las migraciones internas a la provincia estaban nutridos por el arribo

${ }^{23}$ Minoridad. Serie A, T. 1, 1962/1964, Res. 36, 11/2/63. AG, Argentina. El instituto tuvo una singular participación en las entregas de niños en adopción en aquellos años, tema del que me ocupé en otro trabajo (Gentili, 2017).

${ }^{24}$ La sexualidad y los embarazos de estas jóvenes son aspectos importantes pero por razones de espacio no he podido considerarlos en estas páginas.

${ }^{25}$ Centro de Documentación Histórica. Fondo Menores. Caja 9, exp. 12; caja 15, exp. 15 y 18; caja 16, exp. 10; caja 22, exp. 38 y 42; caja 23, exp. 22 y caja 24, exp. 43. AGTC, Argentina.

${ }^{26}$ Centro de Documentación Histórica. Fondo Menores. Caja 2, exp. 17; caja 15, exp. 14; caja 23, exp. 25 y caja 24, exp. 35. Agtc, Argentina.

${ }^{27}$ Centro de Documentación Histórica. Fondo Menores. Caja 24, exp. 44. AGTC, Argentina. 
de población procedente de las regiones del litoral pampeano, representando las provincias del noroeste y noreste tan sólo el $15.3 \%$ de los arribos ${ }^{28}$ El mapa trazado por las colocaciones es lo suficientemente pequeño para no tener un valor estadístico, pero resulta particularmente significativo de los patrones culturales que había cifrado la configuración de la Argentina moderna, donde las regiones del norte de las que provenían esas chicas quedaron asociadas, en el imaginario, a lo "atrasado", en oposición a la modernización económica y social vivida en las regiones del litoral.

Habiendo o no llegado de otras latitudes, las experiencias de estas jóvenes revelan que su paso por el asilo del Buen Pastor y otros institutos a cargo de la misma congregación religiosa (como el Hogar de Menores Madres y el Hogar Santa Cruz), eran en aquellos años sinónimo de una colocación. Habíamos visto ya que estas ocurrían en poco más de la mitad de los egresos institucionales. El cuadro 3 nos muestra ahora la particular gravitación que tenía en ellas aquel asilo y su congregación: de las 44 colocaciones habidas tras una concertación institucional, 23 tenemos certeza de que fueron arbitradas por aquellas monjas y no es iluso pensar que también ellas estuvieron presentes en aquellas ocho que no revelan de qué instituto estaban saliendo. La cuantificación permite constatar la impresión que María Gabriela Lugones (2004) tuviera al relevar un corpus seleccionado de estas fuentes: entre las monjas del asilo y las autoridades judiciales existía un verdadero circuito de provisión de trabajo doméstico.

Vimos además que el Buen Pastor era también sinónimo de "malos comportamientos". Apelar a una internación en ese asilo formaba parte de los recursos disciplinarios de los que disponían tanto los encargados de los institutos como del abanico de sanciones desplegadas por el mundo familiar, ocasiones en las que la puerta también quedaba abierta hacia el servicio doméstico ${ }^{29}$ Portarse mal era también sinónimo de haberse "fugado" de la casa de sus patrones, situaciones que podían derivar en una nueva internación en el asilo y en nuevas colocaciones; lo vimos al conocer la historia de Carmen y podemos ahora aseverarlo como un dato recurrente al volver a revisar los dos

\footnotetext{
${ }^{28}$ Según el censo de 1960, de las regiones pampeanas y el litoral arribó el 69.3\% de los migrantes a Córdoba; de la región de Cuyo 10.1\% y no se obtuvieron datos de procedencia del $4.3 \%$ de los migrantes. Elaboración propia a partir del Censo Nacional de Población (1960, t. IV, p. L).

${ }^{29}$ En al menos cuatro procesos el ingreso de las chicas al Buen Pastor fue pedido por sus padres o familiares por "mal comportamiento"; Centro de Documentación Histórica. Fondo Menores. Caja 10, exp. 28; caja 17, exp. 6; caja 23, exp. 11 y caja 24, exp. 10. AGTC, Argentina.
} 


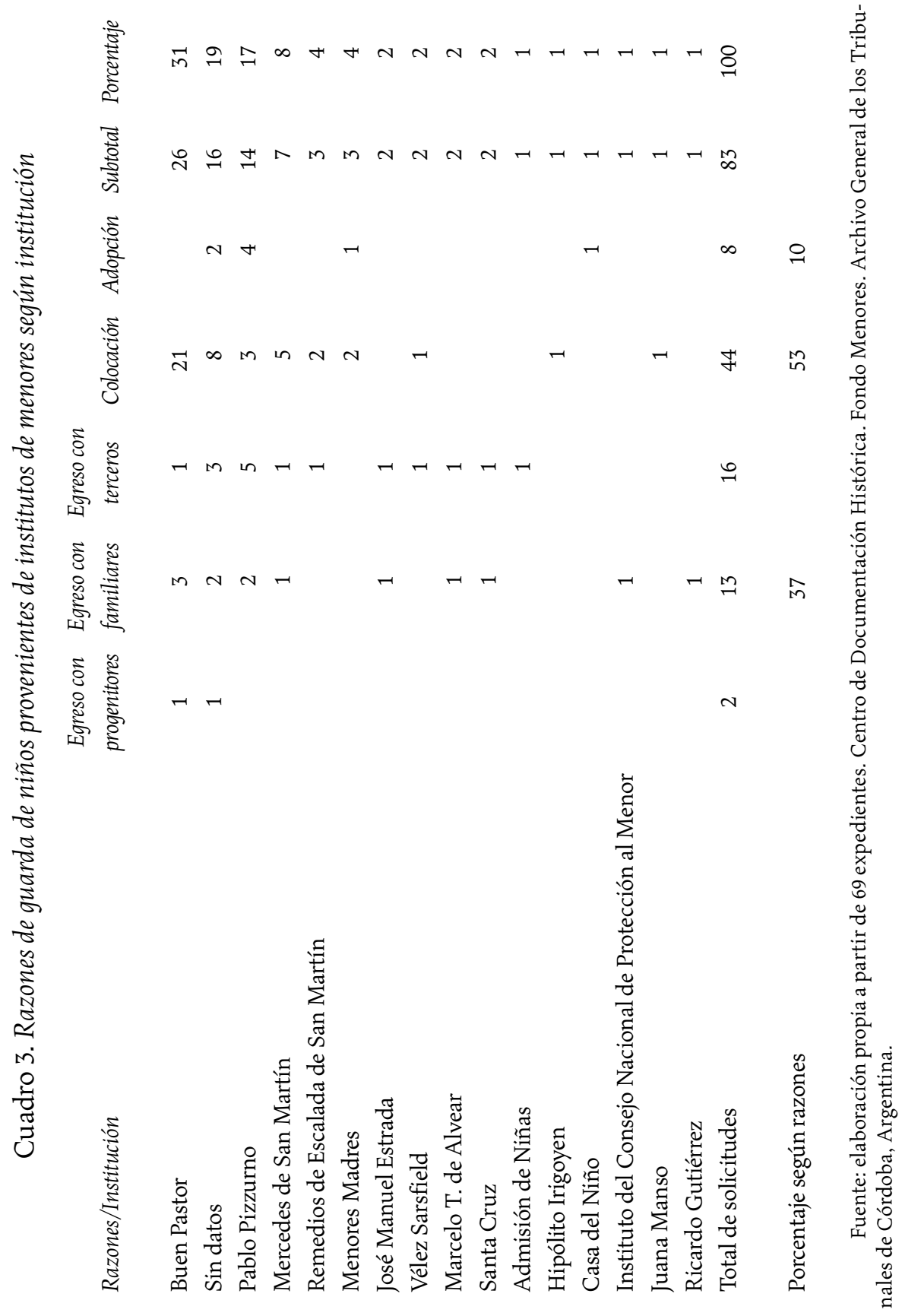


primeros cuadros de los procesos de guarda. Si el primero nos mostraba que 59 solicitudes habían sido concertaciones laborales y el segundo nos decía que habían sido 44 las chicas y los chicos involucrados, el resultado nos revela que en un cuarto de ellos (quince procesos) se arbitró en más de una oportunidad este destino laboral recurrente; esto es, se concedieron numerosas y sucesivas guardas a distintos patrones, argumentándose, cuando se brindaba alguna explicación, no sólo desacuerdos de los empleadores respecto del comportamiento de las chicas, sino también de ellas respecto del trabajo y del salario. El caso más extremo fue el de Alicia, una niña de catorce años que salió siete veces del Buen Pastor como empleada doméstica entre fines de 1960 y mediados de 1970, hasta que logró retomar el contacto con su familia y quedó bajo la guarda de una prima. ${ }^{30}$

La "fuga" admitía así otros significados. Como sostiene Ehrick (2009) en su análisis de estas experiencias juveniles en el Uruguay de principios del siglo $\mathrm{xx}$, las oficinas judiciales resultaban tanto un lugar donde los patrones podían "desentenderse honradamente" de sus dependientes, como una nueva herramienta de la que disponían las jóvenes para mejorar sus circunstancias, o al menos negociarlas. El proceso de Carmen daba cuenta de eso en las ocasiones en que acudía por sí misma a la Dirección de Menores tras irse de la casa de sus guardadores. También lo hacían otras jóvenes que recurrían a la concertación laboral como una forma de resolver sus conflictos familiares. En 1973, Adriana, de 19 años, se presentó en el juzgado pidiendo quedar a cargo de una mujer porque tenía problemas con la familia que la criara desde los cinco años. Desde que había fallecido su "madre de crianza habían comenzado a hacerle la vida imposible, a darle malos tratos e incluso uno de los hijos (casado) la perseguía constantemente faltándole el respeto". ${ }^{31}$ También Marta, que creía tener catorce años y recurría al juzgado "para que la pongan en otra parte", diciendo que hasta los ocho años había vivido con sus padres,

luego la internaron en un colegio de Hermanas (frente a la terminal de ómnibus) ignorando la causa y de allí la sacaron para ir a trabajar en la casa de la señora Pérez Rodríguez donde permaneció tres años y ocho meses, nunca le pagaron y la vestían con ropas usadas de la sobrina y de la hija; no queriendo permanecer más en dicho hogar, pasando entonces a poder del Dr. Castro don-

${ }^{30}$ Centro de Documentación Histórica. Fondo Menores. Caja 23, exp. 25. AGTC, Argentina.

${ }^{31}$ Centro de Documentación Histórica. Fondo Menores. Caja 5, exp. 22. AGTC, Argentina. 
de estuvo ocho días y como no le gustaba pidió que la trajeran al Juez [...]. De los padres nunca supo nada, por lo tanto ignora si han muerto o están vivos.

Las autoridades ordenaron su internación en abril de 1964 y Marta entró en un internado religioso. Un año después, sin explicitaciones de su traslado, salía del Buen Pastor como doméstica a una casa de familia. ${ }^{32} \mathrm{El}$ testimonio de una joven que acudía al juzgado para contar lo que pasaba con otra chica que estaba en la misma casa que su hermana, deja asentado en 1964 de manera explícita que las oficinas judiciales eran un recurso del que se disponía para mejorar las condiciones en que se cumplían esas tareas: "era tratada sin ninguna consideración, puesto que dormía en el suelo, que a su hermana la trataban de igual manera hasta que la misma presentó su situación al señor defensor de menores quien la llamó al orden a la señora [que la empleaba], tratándola desde ese momento de otra forma [...]. Que la niña presentaba el aspecto de un animalito asustado, que sus ropas se veían en mal estado." 33

Como puede percibirse en el proceso de Carmen, los expedientes decían poco sobre las personas que sacaban a estas chicas del asilo del Buen Pastor. Los episodios judiciales de esas entregas eran sumamente escuetos y opacos, alguien llegaba al juzgado pidiendo la guarda de una joven y, consignándose que era un deseo de ella salir a trabajar, el pedido era concedido sin más preámbulos. De las casas en que estas chicas eran colocadas tenemos tenues impresiones a partir de un puñado de procesos, porque los informes que retrataban esos espacios solían no practicarse y en ocasiones llegar cuando las chicas ya se habían ido, concentrándose entonces en las "inexplicables" razones de sus evasiones o en "el mal comportamiento" que habrían tenido. La imagen de aquella chica que "tenía el aspecto de un animalito asustado" y era "tratada sin ninguna consideración”, convivía con la de otra que "hacía las tareas del hogar pero como eran sólo dos personas grandes el trabajo era poco", salía con la dueña de la casa y "su mayor diversión era ver televisión todas las tardes" con ella, le pagaban 1000 pesos, de los cuales depositaban 200 para su ahorro y el resto lo gastaba en comprarse ropa, y estaba "muy conforme con sus patrones" porque la trataban con mucha con-

32 Centro de Documentación Histórica. Fondo Menores. Caja 16, exp. 9. AgTc, Argentina.

33 Centro de Documentación Histórica. Fondo Menores. Caja 17, exp. 18. AgTC, Argentina. 
sideración..$^{34}$ Incluso traducidas en las líneas de la asistente social y expresadas en presencia de sus patrones, las palabras de algunas chicas dejaban entrever que en esos espacios el trato podía ser cordial -hasta "cariñoso" ${ }^{35}$-, y el trabajo no necesariamente agobiante. Entre aquel y este otro extremo del retrato judicial de esos escenarios de trabajo y convivencia, se colaban situaciones intermedias: la patrona le estaba "enseñando a leer y escribir" pero la chica "casi no tenía tiempo para dedicarse a esa tarea indispensable dado que el trabajo de la casa era grande y agobiador", creyendo el asistente que "el trato que recibía no debía ser del todo bueno" porque cuando recorría las dependencias de servicio la dueña de casa le decía que "era raro [su] interés por esta clase de gente". ${ }^{36}$

De la narrativa judicial ha desaparecido la voz "criada" que antaño daba estatus a esa relación que en sus inicios estuviera en manos del mundo familiar. Su reemplazo por la voz colocación cifraba los alcances ambiguos de esa relación ahora laboral pero evidentemente híbrida, a mitad de camino entre el acogimiento y el empleo, evidenciada por la designación de esos patrones como guardadores de los que se esperaba que ofrecieran un espacio donde esas jóvenes pudieran vivir y les enseñaran a comportarse como chicas buenas y trabajadoras serviciales.

\section{MUTACIONES EN LA LARGA DURACIÓN}

La historia de Carmen no sólo comparte rasgos con las de otras que por aquellos años transitaron los juzgados de menores de Córdoba, también lo hace con las de muchísimas otras que desde épocas coloniales pasaron por comisarías, defensorías de menores, asilos e internados. Por motivos singulares pero emparentados, son historias de niñas ubicadas por sus padres o por autoridades de diverso cuño en casas donde se las empleaba en las tareas domésticas a cambio de comida, vestido $y$, en ocasiones, pequeñas sumas de dinero. Traídas de lejos, de las fronteras que separaban en la cosmovisión decimonónica el mundo bárbaro del civilizado, del interior del país, continuaban hacia mediados del siglo xx ofreciendo un servicio valorado y mal remune-

\footnotetext{
34 Centro de Documentación Histórica. Fondo Menores. Caja 22, exp. 30. AGTc, Argentina.

35 Centro de Documentación Histórica. Fondo Menores. Caja 9, exp. 9. AGTC, Argentina.

36 Centro de Documentación Histórica. Fondo Menores. Caja 25, exp. 7. AGTC, Argentina.
} 
rado con el que algunas familias organizaban su vida cotidiana: la limpieza de la casa, el cuidado de los niños, la compañía de los ancianos, los mandados; de vez en cuando, saciar los deseos sexuales de sus patrones. Del origen familiar de esa práctica a su configuración institucional existieron límites difusos, fronteras porosas como las que cifran las relaciones de complementación, disputa y negociaciones de ambos órdenes de la vida social.

\section{Las colocaciones en el pasado}

De las autoridades asilares y judiciales que arbitraban estos destinos laborales había tomado el nombre de colocación, en referencia a la acción que cumplían al velar por los intereses de los menores puestos a su disposición. Un reglamento virreinal de principios del siglo xix la había encomendado a los alcaldes de barrio, considerándose una manera de proporcionar a estas niñas "un modo de subsistir a expensas de su trabajo personal y aplicación", un "medio seguro de evitar que se entreguen a los vicios y después a los delitos" (citado en Larrandart, 1991, p. 193). Con ese mismo sentido continuaba propiciándose a principios del xx como función explícita de los defensores de menores -figura colonial incorporada al ordenamiento jurídico nacional-, a quienes en Córdoba se les pedía que trataran de "colocarlos convenientemente, de modo que sean educados o se les dé algún oficio o profesión susceptible de proporcionar los medios de vivir" ${ }^{37}$

Estudios sobre las sociedades coloniales y poscoloniales revelan que las desavenencias entre los padres o entre estos y los guardadores de los niños eran una de las principales razones que desembocaban en los procesos judiciales que involucraban a la infancia; y que en una u otra circunstancia, la entrega estaba signada por la importancia que tenían como fuerza de trabajo (Cicerchia, 1990 y 1994; Moreno, 2004). En consonancia con eso, para el contexto cordobés de los siglos XVII al xIx, Ghirardi (2008) sostiene que la utilidad de los niños como fuerza de trabajo ocupaba el primer plano de esas disputas, pero ello no significaba que el afecto no fuera un componente de las relaciones entre adultos y niños. Si las entregas eran en ocasiones signo de servidumbre propiciada por autoridades proclives a quitarles los niños a

${ }^{37}$ Art. $5^{\circ}$, acuerdo reglamentario del Tribunal Superior de Justicia de Córdoba, 15 de junio de 1926. 
padres pobres, los progenitores reclamaban la posibilidad de decidir la colocación de sus hijos, pudiendo percibir parte de sus salarios y tenerlos cerca en casos de enfermedad o necesidad de colaboración.

Quienes estudiaron las memorias de las defensorías de menores de principios de siglo en Buenos Aires (Allemandi, 2015; Freidenraij, 2015; Guy, 2002) y la labor desplegada por las instituciones asilares (Aversa, 2010 y Villalta, 2012 para Buenos Aires; Flores, 2004 para el contexto cordobés), sostienen que estos espacios hicieron de la colocación en el servicio doméstico uno de sus principales objetivos. Las mujeres eran la mayor parte de la población de las defensorías y la multiplicidad de destinos laborales masculinos (fábricas, talleres, comercios, establecimientos rurales, fuerzas armadas) contrastaba con la universalidad del trabajo doméstico como ocupación femenina. La alternancia entre periodos de trabajo, fugas y encierro en instituciones correccionales, era la circulación característica de estas jóvenes en su tránsito por las defensorías (Aversa, 2010; Freidenraij, 2010; 2015). La recurrente presencia femenina, la univocidad del trabajo doméstico como destino laboral y aquella alternancia de encierro, fuga y colocación, eran aún rasgos característicos de las colocaciones arbitradas en los juzgados hacia mediados del siglo xx.

\section{Una prohibición tenue}

Pero no sólo eran continuidades las que atravesaban a estas prácticas de tan larga duración. Vimos que en los años sesenta del siglo xx las colocaciones no eran numerosas en comparación con las restantes guardas concedidas, que sólo en contadas ocasiones involucraban a niñas menores de doce años y que las oficinas llamadas a velar por los intereses de estas niñas prohibieron en 1958 que su personal las retirara con ese propósito. Esa prohibición se volvió ley en 1966, sosteniéndose que había que "terminar con los viejos resabios de las Defensorías de antaño que con carácter paternalista protegían al menor entregándolo para el servicio doméstico [...] sin descartar la posibilidad de que las condiciones intelectuales de un menor sólo le permitan dicho tipo de trabajo, a ello debe llegarse cuando están agotadas todas las instancias pedagógicas". ${ }^{38}$

${ }^{38}$ Diario de Sesiones de la Cámara de Diputados, (1965, t. III), Estatutos de la minoridad, p. 2 582. Biblioteca de la Legislatura de Córdoba, Argentina. 
La prohibición tenía antecedentes legislativos en el orden nacional. Los primeros proyectos y debates parlamentarios se remontan a la segunda década del siglo xx. Limitadas entonces a menores de catorce años y preocupadas por la incompatibilidad que encontraban entre el desempeño en esas tareas y su escolarización, las voces promotoras y opositoras que se levantaron en los recintos parlamentarios tenían en la mira a los arbitrios familiares e institucionales de colocación, prohibiéndose en 1924 el empleo de menores de catorce en el servicio doméstico. Como sostiene Allemandi (2015), aquella prohibición que tuvo en el centro de su preocupación a la población infantil de esta esfera laboral, fue el primer antecedente de regulación de una actividad que recién consiguiera contar con un marco normativo específico en 1956. ${ }^{39}$ Por otra parte, la sanción en 1948 de la primera ley de adopción del país fue presentada como una alternativa para desterrar aquellas prácticas, abriendo la posibilidad de que los niños y las niñas fueran incorporados jurídicamente en calidad de hijos y no ya como "criados" (Villalta, 2012).

Sin olvidar que estamos ante restos y no una serie completa de expedientes, la cantidad de guardas otorgadas a patrones antes y después de su prohibición, muestra una declinación: las encontramos en 36 solicitudes tramitadas entre 1956 y 1965, y entre 1966 y 1974 fueron 23. Pero si recordamos que las guardas por este motivo fueron menos numerosas que las restantes, podría decirse que la prohibición llegaba por añadidura a un proceso de cambio que ya venía gestándose.

\section{Otras alternativas}

La Dirección de Menores comenzó en aquellos años a concertar otros destinos laborales para las jóvenes internadas en sus institutos: se les conceden becas para terminar sus estudios de enfermería o realizar tareas administrativas en la repartición, ${ }^{40} \mathrm{y}$ también una pequeña suma de dinero para solven-

\footnotetext{
39 Sobre las particularidades del régimen especial que reguló el servicio doméstico en Argentina desde 1956 y por más de 50 años, véase Pérez (2015) y Tizziani (2013).

${ }^{40}$ Minoridad. Serie A, 1965, T. 3, Res. 201 A, 17/12/65 y Res. 202 A, 17/12/65. AG, Argentina.
} 
tar los gastos de sus fiestas de casamiento, destino matrimonial que otorgaba otra vía de egreso. ${ }^{41}$

En algunos institutos, como en el Hogar Santa Cruz por el que pasó Carmen, se daban "Cursos de Formación Profesional Acelerada", un título pretensioso para una enseñanza clásica: junto a clases de cocina se dictaban otras de peluquería y corte y confección. ${ }^{42}$ Ante las cámaras de un noticiero local hablaba de esto en 1972 la directora del instituto, una monja licenciada en psicología, que explicaba que se trataba de una "formación elemental" de carácter "limitado", decía, "por la misma capacidad de la menor, que puede ocurrir que no sea suficientemente elevada, de manera que se le da en la medida de lo posible". ${ }^{43}$ Agregaba, además, que las permanencias prolongadas en los institutos podían producir "una disminución en el rendimiento intelectual" y que en la "esfera afectiva" podía producirse un "aumento de la agresividad". Así, mientras la legislación limitaba la salida de un instituto con destino al servicio doméstico cuando se hubieran agotado todas las instancias pedagógicas, la historia de Carmen y este reportaje ponían en evidencia que las "condiciones intelectuales" de las niñas y los niños se veían notoriamente perjudicadas por la internación misma, que traía aparejadas experiencias de vida en las que escaseaban el afecto y los estímulos.

\section{Con disimulo}

Entre tantos indicios que hacían del servicio doméstico un destino del que ya no podía hablarse con franqueza, los documentos reunidos en los expedientes pasaron de contener grandes sellos estampados en los que se completaban los datos específicos de la ubicación de una niña-marca registrada de una acción recurrente- a dejar de nombrarla; y los motivos de las entregas comenzaron a aparecer de soslayo en informes y declaraciones posteriores. Cuando los defensores fueron reemplazados por magistrados la voz guarda reemplazó a colocación, pátina que suavizó la textura de una práctica que pervivía, porque a pesar de haber desaparecido como referencia explícita del

41 Minoridad. Serie A, 1970, T. 6, Res. 77 A, 16/10/70; serie B, 1970, T. 33, Res. 2.673 B, 5/1/70 y 1972, T. 47, Res. 4.860 B, 2/11/72. Ag, Argentina.

${ }^{42}$ Minoridad. Serie B, T. 40, 1971, Res. 3.741 B, 15/9/71. AG, Argentina.

43 Archivo Fílmico de Canal 10. Cassette 137, noticia 43, 1972, título original: Minoridad Hogar Santa Cruz. CDA, Argentina. 
mandato judicial, el destino que se arbitraba continuaba siendo el mismo. La preocupación que las autoridades mostraban por conocer el trato que las niñas recibían por parte de sus guardadores cuando no eran miembros de su parentela, por el tipo de tareas que desempeñaban, o por dejar asentado que sería un deseo de ellas salir a trabajar, fueron las maneras solapadas con que se mostró en los años sesenta esta práctica antigua. En otras palabras, en el relato judicial, este tipo de trabajo infantil y juvenil ya no era pasible de ser enunciado abiertamente, ni por las autoridades ni por los interesados en las guardas. De allí que no podamos sostener con firmeza que aquellos niños y niñas que salían de los institutos junto a personas ajenas al parentesco biológico bajo distintos acuerdos de "crianza", no involucraran, también, el interés por la colaboración que podían prestar en la organización de la vida familiar; y lo mismo puede decirse de ese segmento de aquellas solicitudes en las que era un arbitrio familiar y no institucional el que la guarda convalidaba.

\section{El valor de la infancia}

Miradas a trasluz de las experiencias pretéritas, las razones de los pedidos de guarda formulados en los años sesenta sugerirían que el lugar preeminente que ocupaba el interés por la fuerza de trabajo infantil había sido reemplazado por el valor de niñas y niños como depositarios de los cuidados que demandan del mundo adulto. Como sostiene Zelizer (1981) para el contexto estadunidense, en el tránsito del siglo XIX al Xx una mutación en el valor de la infancia produjo el paso de los niños de "objetos de utilidad" a "objetos de sentimientos"; del valor económico del niño en tanto fuerza de trabajo que contribuía con el sostenimiento de la familia, a la emergencia del niño sin valor económico pero con una invaluable importancia emocional. Al relacionar las guardas tramitadas en los juzgados hacia los años sesenta con las constataciones de otros estudios sobre las ocasiones en que el trasiego de los niños involucraba una intervención judicial de arbitrio o convalidación, evidenciamos que aquella mutación pareciera estar consolidada; al menos en el repertorio de argumentos esgrimidos ante las autoridades judiciales. Este desplazamiento hacia la importancia de los niños como depositarios de afectos no suponía necesariamente que de ellos no se esperaran contribuciones a la organización de la vida familiar; como la compañía en la vejez y el cuidado de otros niños. Lo que todo parece indicar es que si esos intereses 
existían, habían dejado de enunciarse explícitamente ante y por las autoridades judiciales.

\section{CONCLUSIONES}

Una reducción en la escala de observación, articulada con operaciones de cuantificación y contextualizaciones situadas, nos permitió reconocer los rasgos asumidos por las colocaciones hacia los años sesenta del siglo $\mathrm{xx}$ : detectar las singularidades y los parecidos de la historia de Carmen respecto de otras chicas que como ellas vivieron esas experiencias. Dada la ausencia de trabajos sobre este mismo periodo en otras regiones del país, resulta imposible señalar las especificidades del escenario cordobés. Ello no inhibe, sin embargo, la posibilidad de cerrar estas páginas con algunas afirmaciones sobre las transformaciones del fenómeno en la larga duración.

Una nueva sensibilidad respecto del valor de la infancia -que hacia los años sesenta ha cristalizado no sólo en el gobierno que las familias hacen de ellas sino también en aquel otro que despliega el Estado-permite entender el carácter asumido por la colocación de niñas y jóvenes en el servicio doméstico hacia la segunda mitad del siglo xx. Si en el pasado remoto estuvo asociada a una forma de organización de la vida familiar que diera lugar a la figura del "criado" y la "criada", y a principios de siglo era "la" actividad de las defensorías de menores, hacia la segunda mitad la encontramos en un lugar marginal al interior de los distintos arreglos de tenencia de niños y jóvenes, marcadamente feminizada y particularmente asociada a chicas que transitaban por espacios específicos del entramado institucional de la minoridad. En los años veinte la legislación había corrido el umbral a los catorce años de edad para la posibilidad del arbitrio familiar e institucional de ese destino, haciendo de la infancia el sujeto detonante del primer ensayo de reglamentación del servicio doméstico en general. Cuarenta años después, la narrativa judicial sólo excepcionalmente admitía de manera explícita que una niña que tuviera menos de catorce años se viera envuelta en ese vínculo de convivencia y trabajo. Y cuando lo hacía o dejaba percibir que lo estaba haciendo, tenía como protagonistas a quienes transitaban espacios singulares de internación, no sólo por estar a cargo de los más antiguos elencos institucionales -las congregaciones religiosas y en particular la del Buen Pastor-, sino también por su asociación simbólica y material a un lugar del que el 
mundo familiar y el restante conjunto de instituciones a cargo del Estado disponían para quienes debían cumplir "penitencia" por su "mal comportamiento". Con trayectorias escolares erráticas y dificultades de aprendizaje derivadas de la falta de estímulos y afectos que la propia experiencia de internación acarreaba, el camino a la colocación quedaba moralmente abierto a los ojos de una legislación que lo prohibía al mismo tiempo que lo habilitaba al amparo del escaso rendimiento intelectual atribuido a esas jóvenes.

Así, de principios a mediados del siglo xx estas prácticas adquirieron el tono de lo que Raymond Williams (2009) define como un rasgo residual de la cultura: dejaron de ser un componente dominante del quehacer judicial para manifestarse como una herencia del pasado con fuerza activa en aquel presente. Leídas en perspectiva, las historias de estas niñas y jóvenes, como la del epígrafe que inaugura estas páginas, muestran las veladuras que se imprimieron a las colocaciones hacia los años sesenta. Con finas capas de tinta transparente que suavizan los tonos de lo pintado, aquella nueva sensibilidad en torno a la infancia fraguó un relato judicial que pasó de propiciarlas a disimularlas. A mostrarlas de soslayo o singularmente vinculadas a espacios específicos de internación en los que pervivían menos disimuladamente en una época en que ya no era admisible su reconocimiento explícito. Había dejado de ser un destino recurrente, fue prohibido y se ensayaron (tímidamente) otras alternativas, pero el servicio doméstico, velado, continuaba gravitando como destino de algunas niñas que transitaban los juzgados de menores.

\section{LISTA DE REFERENCIAS}

Allemandi, C. (octubre, 2015). Niños sirvientes y "criados": el trabajo infantil en el servicio doméstico (ciudad de Buenos Aires, fines del siglo xix-principios del xx). Cuadernos del IDES, 30, 11-38. Recuperado de http://ides.org.ar/wp-content/ uploads/2012/03/Cuadernos-del-IDES-N\%C2\%BA-30-Octubre-2015.pdf

Allemandi, C. (2017). Sirvientes, criados y nodrizas: una historia del servicio doméstico en la ciudad de Buenos Aires: fines del siglo xIx y principios del xx. Buenos Aires: Teseo.

Aversa, M. (2010). Colocaciones y destinos laborales en niños y jóvenes asilados en la ciudad de Buenos Aires (1890-1900). En L. Lionetti y D. Míguez (comps.), Las infancias en la historia argentina. Intersecciones entre prácticas, discursos e instituciones (1890-1960) (pp. 35-52). Rosario: Rosario. 
Bjerg, M. y Boixadós, R. (2004). Tendencias en la historia de la familia en Argentina. En M. Bjerg y R. Boixadós (eds.), La familia campo de investigación interdisciplinario. Teorías, métodos y fuentes (pp. 171-186). Buenos Aires: Universidad Nacional de Quilmes.

Blum, A. (1998). Public welfare and child circulation, México City, 1877 to 1925. Journal of Family History, 23(3), 240-271.

Bourdieu, P. (1997). Razones prácticas. Sobre la teoría de la acción. Barcelona: Anagrama. Censo Nacional de Población (t. IV) (1960). República de Argentina: Dirección Nacional de Estadísticas y Censos, Secretaría de Estado y Hacienda, Poder Ejecutivo Nacional.

Cicerchia, R. (1990). Vida familiar y prácticas conyugales. Clases populares en una ciudad colonial, Buenos Aires, 1800-1810. Boletín del Instituto de Historia Argentina y Americana "Dr. E. Ravigniani", 3(2), 91-109.

Cicerchia, R. (1994). Familia: la historia de una idea. Los desórdenes domésticos de la plebe urbana porteña, Buenos Aires, 1776-1850. En C. Wainermar (comp.), Vivir en familia (pp. 49-72). Buenos Aires: UnICEF/Losada.

Cosse, I. (2009). La historia de la familia en la Argentina del siglo xx: nuevas perspectivas de un campo en construcción. Anuario IEHS, 23, 343-355.

Cosse, I. (2012). Pareja, sexualidad y familia en los años sesenta. Buenos Aires: Siglo XXI Editores.

Cosse, I., Llobet, V., Villalta, C. y Zapiola, M. (2012). Introducción. En I. Cosse, V. Llobet, C. Villalta y M. Zapiola (eds.), Infancias: politicas y saberes en Argentina y Brasil, siglos XIX y XX (pp. 11-28). Buenos Aires: Teseo.

Diario de Sesiones de la Cámara de Diputados (t. III) (1965). Argentina: Poder Legislativo de la Provincia de Córdoba.

Ehrick, C. (2009). Madres juveniles, paternalismo y formación del Estado en Uruguay, 1910-1930. En Y. Eraso (comp.), Mujeres y asistencia social en Latinoamérica, siglos XIX y XX. Argentina, Colombia, México, Perú y Uruguay (pp. 131-165). Córdoba: Alción.

Farge, A. (1991). La atracción del archivo. Valencia: Edicions Alfons el Magnánim, Institució Valenciana d'Estudis i Investigació.

Farge, A. y Revel, J. (1998). Lógica de las multitudes. Rosario: Homo Sapiens Ediciones. Fávero Arend, S. (2005). Filhos de criação: uma história dos menores abandonados no Brasil (década de 1930). (Tesis de posgrado). Universidad de Río Grande del Sur, Brasil. Recuperado de www.lume.ufrgs.br/bitstream/handle/10183/7188/000496541. pdf?sequence $=1$ 
Flores, M. (2004). Expósitos y abandonados. La práctica social de colocación de niños. La Casa Cuna de Córdoba: 1884-1950. Córdoba: Universitas.

Fonseca, C. (1998). Caminos de adopción. Buenos Aires: Eudeba.

Foucault, M. (2009). La "gubernamentalidad”. En G. Giorgi y F. Rodríguez (comps.), Ensayos sobre biopolítica. Excesos de vida (pp. 187-215). Buenos Aires: Paidós.

Freidenraij, C. (2010). La minoridad en disputa. Intervenciones femeninas en torno a la estructuración de las políticas de menores en los años treinta. Ponencia presentada en el Workshop: Mujeres, políticas sociales, tramas estatales (1850-1940). Buenos Aires: Universidad de Buenos Aires/Universidad Nacional de La Pampa.

Freidenraij, C. (2015). La niñez desviada. La tutela estatal de niños pobres, huérfanos y delincuentes. Buenos Aires, 1890-1919. (Tesis de doctorado). Facultad de Filosofía y Letras, Universidad de Buenos Aires, Argentina.

Gentili, A. (2015). Un fuero híbrido. Juzgados de menores, precedentes y prácticas en Córdoba, Argentina, primera mitad del siglo xx. En M. R. Polotto, T. Keiser y T. Duve (eds.), Derecho privado y modernización. América Latina y Europa en la primera mitad del siglo xx (pp. 227-241). Frankfurt: Max Planck Institute for European Legal History. Open Access Publication www.rg.mpg.de/publikationen/gplh_2

Gentili, A. (2017). Relatos judiciales, Estado y sociedad: orígenes familiares de niños adoptados en Córdoba en los sesenta. Población \& Sociedad, 24(2), 95-127. Recuperado de http://www.poblacionysociedad.org.ar/include/ABS/abs_v24_Gentili. php

Ghirardi, M. (2008). Reclamados, embargados, cobrados y cedidos. La niñez como ¿valor de uso? en Córdoba, Argentina, siglos XVII y XVIII. En M. Ghirardi (coord.), Familias iberoamericanas ayer y hoy. Una mirada interdisciplinaria (pp. 251-283). Río de Janeiro: Asociación Latinoamericana de Población.

Guy, D. (2002). The state, family, and marginal children in Latin America. En T. Hech, Minor omissions: Children in Latin American history and society. Wisconsin: University of Wisconsin Press.

Hareven, T. (1995). Historia de la familia y la complejidad del cambio social. Boletín de la Asociación de Demografía Histórica, XIII(1), 101-149.

Larrandart, L. (1991). Prehistoria e historia del control socio-penal de la infancia. En E. García Méndez y M. del C. Bianchi (comps.), Ser niño en América Latina: de las necesidades a los derechos. Buenos Aires: Galerna.

Lugones, M. y Rufer, M. (2004). Fuentes en extinción: estudio cualitativo de procesos judiciales de los Tribunales de Menores de Córdoba. Miradas Alternativas. Análisis Multidisciplinario del Fenómeno Jurídico, 2, 37-44. 
Lugones, M. (2004). Uma "visita" aos "expedientes": os processos judiciais referentes aos menores, Córdoba, Argentina, na metade do século xx. (Tesis de maestría). Universidad Federal de Río de Janeiro/Museo Nacional/Programa de Postgrado en Antropología Social.

Milanich, N. (2009). Children of fate. Childhood, class and the State in Chile, 1850-1930. Durham y Londres: Duke University Press.

Moreno, J. (2004). Historia de la familia en el Río de la Plata. Buenos Aires: Sudamericana.

Ortiz Bergia, M. J. (2012a). La construcción del Estado social en el interior argentino. Cambios y continuidades en las políticas sociales en Córdoba, 1930-1955. (Tesis de doctorado). Facultad de Filosofía y Humanidades, Universidad Nacional de Córdoba.

Ortiz Bergia, M. J. (2012b). Asistencia benéfica y gobiernos peronistas en Córdoba. En C. Biernart y K. Ramacciotti (eds.), Políticas sociales, entre demandas y resistencias: Argentina 1930-1970 (pp. 67-96). Buenos Aires: Biblos.

Pérez, I. (2014). Género y derechos laborales: servicio doméstico y trabajo doméstico no remunerado en la justicia laboral en Argentina (1956-1974). Páginas, 6(12), 67-82. Recuperado de http://revistapaginas.unr.edu.ar/index.php/RevPaginas/ article/view/19/19

Pérez, I. (2015). Un "régimen especial" para el servicio doméstico. Tensiones entre lo laboral y lo familiar en la regulación del servicio doméstico en la Argentina, 1926-1956. En El trabajo doméstico: entre regulaciones formales e informales. Miradas desde la historia y la sociología (pp. 44-67) (Cuadernos del IDES, 30). Recuperado de http://ides.org.ar/wp-content/uploads/2012/03/Cuadernos-del-IDES-N\%C2\%BA-30-Octubre-2015.pdf

Premo, B. (2008). How Latina America's History of Childhood Came of Age. The Journal of the History of Childhood and Youth, 1(1), 63-76.

Rapp, R. (1979). Household and Family. En Rayna Rapp, Ellen Ross y Renate Bridenthal, "Examining family history". Feminist Studies, 5(1), 175-181.

Remedi, F. (2012). Esta descompostura general de la servidumbre. Secuencia. Revista de Historia y Ciencias Sociales, (84), 41-69. DoI: 10.18234/secuencia.v0i84.1168

Revel, J. (editor) (2015). Juegos de escalas. Experiencias de microanálisis. Buenos Aires: Universidad Nacional de San Martín.

Sosenski, S. (2010). Niños en acción. El trabajo infantil en la ciudad de México (19201934). México: El Colegio de México.

Suriano, J. (2007). El trabajo infantil. En S. Torrado (comp.), Población y bienestar en la Argentina del primero al segundo Centenarios. Una historia social del siglo xx (t. II). Buenos Aires: Edhasa. 
Tizziani, A. (2013). El Estatuto del Servicio Doméstico y sus antecedentes: debates en torno a la regulación del trabajo doméstico remunerado en la Argentina. Nuevos Mundos, Mundos Nuevos, Questions du temps présent. DoI: 10.4000/ nuevomundo.65153

Twinam, A. (2009). Vidas públicas, secretos privados. Género, honor, sexualidad e ilegitimidad en la Hispanoamérica colonial. Buenos Aires: Fondo de Cultura Económica.

Vianna, A. (2010). Derechos, moralidades y desigualdades. Consideraciones acerca de procesos de guarda de niños. En C. Villalta (comp.), Infancia, justicia y derechos humanos (pp. 21-72). Bernal: Universidad Nacional de Quilmes.

Villalta, C. (2010). Imitar a la naturaleza. La adopción de niños en los años '60: entre ficciones legales y prácticas consuetudinarias. En I. Cosse, K. Felitti y V. Manzano (eds.). Los '60 de otra manera. Vida cotidiana, género y sexualidades en la Argentina (pp. 89-129). Buenos Aires: Prometeo Libros.

Villalta, C. (2012). Entregas y secuestros. El rol del Estado en la apropiación de niños. Buenos Aires: Editores del Puerto y cels.

Williams, R. (2009). Marxismo y literatura. Buenos Aires: Las Cuarenta.

Zelizer, V. (1981). The price and value of children: The case of children's insurance. American Journal of Sociology, 86(5), 1036-1056.

\section{OTRAS FUENTES}

AG Archivo de Gobierno, Argentina.

Agtc Archivo General de los Tribunales de Córdoba, Argentina.

CDA Centro de Conservación y Documentación Audiovisual, Facultad de Artes y Facultad de Filosofía y Humanidades, Universidad Nacional de Córdoba, Argentina. 